\title{
Effects of acute caffeine ingestion on futsal performance in sub-elite players
}

Álvaro López-Samanes ${ }^{1}$, Victor Moreno-Pérez ${ }^{2}$, Bruno Travassos $^{3,4}$, Juan Del Coso ${ }^{5}$

${ }^{1}$ Exercise Physiology Group, School of Physiotherapy, Faculty of Health Sciences, Universidad Francisco de Vitoria, Madrid, Spain.

${ }^{2}$ Centre for Translational Research in Physiotherapy, Department of Pathology and Surgery, Universidad Miguel Hernández, San Juan, Spain.

3 Research Centre in Sport Sciences, Health and Human Development (CIDESD), Department of Sport Sciences, University of Beira Interior, Covilhã, Portugal

${ }^{4}$ Portugal Football School, Portuguese Football Federation, Oeiras, Portugal,

${ }^{5}$ Centre for Sport Studies, Rey Juan Carlos University, Fuenlabrada, Spain.

\section{Corresponding author:}

Juan Del Coso

Centre for Sport Studies, Rey Juan Carlos Universit

C/ Camino del Molino s/n. Fuenlabrada, 28943. SPAIN

Phone: $34+914884694$

E-mail: juan.delcoso@urjc.es

ORCID: 0000-0002-5785-984X 


\section{ABSTRACT}

Purpose: To date, no previous investigation has studied the effect of acute caffeine ingestion on futsal performance during futsal-specific testing and during a simulated match. Therefore, the aim of this investigation was to establish the effects of acute caffeine intake on futsal-specific tests and match-play running performance in male futsal players. Methods: Sixteen high-performance futsal players participated in a randomised, crossover, placebo-controlled and double-blind experiment. Each player completed two identical trials after ingesting either caffeine $(3 \mathrm{mg} / \mathrm{kg})$ or a placebo (cellulose). The trials consisted of a battery of futsal-specific tests (countermovement jump, 20-m sprint test, and a futsal kicking velocity and accuracy test) followed by a simulated futsal match (2 halves of $7.5 \mathrm{~min}$ ). During the match, players' running performance was assessed with local positioning system devices. Results: In comparison to the placebo, caffeine ingestion increased jump height by $2.8 \%(p=0.048$; ES $=0.29)$ and reduced the time to complete the $20-\mathrm{m}$ sprint test by $-2.2 \%(p=0.044 ; \mathrm{ES}=-0.54)$. Additionally, acute caffeine intake improved the distance covered at above $14.4 \mathrm{~km} / \mathrm{h}$ by $19.6 \%(p=0.021$; $\mathrm{ES}=0.58)$, the number of body impacts by $8.1 \%(p=0.040 ; \mathrm{ES}=0.27)$ and the number of accelerations/decelerations by $4.2 \%(p=0.044 ; \mathrm{ES}=0.57)$ during the simulated futsal match. However, no differences were reported in ball velocity or shooting accuracy in the futsal kicking test. There were no differences in the prevalence of side-effects reported in the hours after the ingestion of the treatments. Conclusion: Three $\mathrm{mg} / \mathrm{kg}$ of caffeine enhanced several physical variables associated with futsal such as jump and sprint performance and improved high-speed running and accelerations/decelerations during a simulated futsal match. Caffeine supplementation with a moderate dose can be considered as an effective ergogenic aid for futsal performance with low prevalence of side effects. 
Keywords: team sports, sports nutrition, external load, supplement, sports performance 


\section{INTRODUCTION}

Futsal is a highly demanding intermittent team sport characterised by the constant repetition of high intensity bouts such as accelerations, decelerations, and cutting movements combined with periods of recovery [1]. Although futsal has similarities with other football disciplines, the unlimited number of substitutions allows a higher intensity during match play because players have the opportunity to recover during substitutions and time-outs. Additionally, the low number of players (i.e., 4 field players plus a goalkeeper) and the reduced available space for play (i.e., $40 \times 20 \mathrm{~m}$ ) demands that elite futsal players must possess a combination of excellent physical, technical and tactical skills [2]. From a physical point of view, futsal performance has been associated with high-levels of agility [3], muscle power [3-5], repeated sprint ability [6,7] and maximal oxygen uptake $\left(\approx 60 \mathrm{ml} \mathrm{kg}^{-1} \cdot \mathrm{min}^{-1} ;[8]\right)$.

Because futsal is characterised by intermittent and explosive demands, strategies to enhance the capacity for repeating high-intensity actions may be crucial for competition [6,7]. Caffeine (1,3,7-trimethylxanthine) is an ergogenic aid with recognised effectiveness to increase performance in team sports with comparable physical demands to futsal such as football [9,10], basketball [11], handball [12], volleyball $[13,14]$ and hockey [15]. In these investigations, caffeine enhanced several aspects of physical performance such as the capacity to repeat sprints, the capacity to jump, the velocity of the ball during shooting and spikes, and player's agility during sport-specific testing. Additionally, acute caffeine intake also improved running performance at high intensity during real and simulated competitions in these and in other team-sports [16]. The benefits of caffeine have been obtained when it is ingested $\sim 1 \mathrm{~h}$ before exercise in a dose of $3 \mathrm{mg}$ per $\mathrm{kg}$ of body mass (i.e., $\mathrm{mg} / \mathrm{kg}$ ). However, the scientific evidence supporting the use of caffeine supplementation to enhance futsal-specific performance is scarce and 
contradictory. Wassmansdorf et al (2012) found that $6 \mathrm{mg} / \mathrm{kg}$ of caffeine did not enhance performance during the Yo-Yo intermittent running test. However, the lack of findings in this study could be attributed to the limited time between the administration of caffeine and the test (i.e., 20 minutes [17]). Recently, Dos Santos Bezerra et al (2021) found that $6 \mathrm{mg} / \mathrm{kg}$ of caffeine, ingested $1 \mathrm{~h}$ before exercise, improved performance during the first phases of a novel high-intensity intermittent exercise test in futsal. However, in that investigation, players experiment a higher decline in performance within the test with caffeine [18] suggesting that the ergogenic effect of caffeine on high-intensity intermittent exercise may be transitory. In the light of these outcomes, it is not clear whether futsal players may benefit from acute caffeine intake. Thus, the aim of this investigation was to establish the effects of acute caffeine intake on futsal-specific tests and match-play running performance in men futsal players. We hypothesised that the ingestion of the caffeine would increase shooting velocity, jump height, sprint velocity and match-play running performance during a simulated game.

\section{METHODS}

\section{Participants}

Twenty high-performance men futsal players from two different Portuguese futsal teams in the 2nd division of the Portuguese National League volunteered to participate in this study. Four participants were unable to complete the two testing sessions and their data were excluded. Therefore, data from the sixteen futsal players who completed the whole experiment were considered for the analysis (age: $27.95 \pm 4.11$ years; height: 173.8 $\pm 6.1 \mathrm{~cm}$; body mass: $71.21 \pm 9.69 \mathrm{~kg}$; futsal experience: $12.4 \pm 2.9$ years). All participants were considered as low caffeine consumers ( $<1 \mathrm{mg} / \mathrm{kg} / \mathrm{day} ;[19])$ as measured with a food 
frequency questionnaire. Sub-elite men futsal players between 18- and 35-years-old were eligible for inclusion. Exclusion criteria were intolerance to caffeine, suffering from any chronic pathology or an injury in the month prior to the investigation and the use of medicines or dietary supplements during the study. Goalkeepers were also excluded due to their different movement patterns during match play. Participants gave their informed written consent to participate, and the study was approved by the Beira Interior University Ethics committee (number CE-UBI-Pj-2020-043) in accordance with the latest version of the Declaration of Helsinki.

\section{Experimental design}

A randomised, double-blind, placebo-controlled crossover experiment was used. An a priori sample size calculation indicated that thirteen participants were needed to obtain statistically significant differences in the number of sprints during a simulated game with three mg of caffeine per $\mathrm{kg}$ of body mass compared to a placebo. This a priori sample size was calculated to obtain an effect size of 0.75 in Cohen's $d$ units (statistical power of $80 \%$ with type I error set at $5 \%$ ), based on a previous investigation that obtained this effect when using the same dose of caffeine during a football match [10]. The required sample size was determined using $G^{*}$ Power software [20]. Each futsal player participated in two identical experimental trials, separated by 48 hours to allow recovery and caffeine washout. In each trial, participants ingested a gelatine capsule with either caffeine ( $3 \mathrm{mg} / \mathrm{kg}$ body mass of caffeine) (Bulk Powders, London, United Kingdom) or a placebo (Cellulose; Guinama, Valencia, Spain). Participants ingested caffeine/placebo in a counterbalanced fashion (in each trial, $50 \%$ of participants ingested placebo and $50 \%$ ingested caffeine) with random assignment to each treatment (Research Randomizer, www.randomizer.org). The dose of caffeine was selected to replicate the treatment used in previous investigations with men team sports players $[10,11]$ The capsule containing 
the treatment was ingested with $150 \mathrm{~mL}$ of water 60 minutes before the onset of the experiment to allow substance absorption. Then, participants performed a battery of futsal-specific tests followed by a simulated futsal match to determine the effects of caffeine on several aspects of futsal physical performance. In both trials, the experimental procedures were performed at the same time of day (18:00-20:00) to avoid the influence of circadian rhythms on caffeine ingestion [21].

\section{Experimental protocol}

One week before the onset of the experiments, a familiarisation session that included the execution of all the tests was carried out. During the 24 hours prior to testing, participants were encouraged to abstain from all dietary sources of caffeine and alcohol and performed light physical activity. They were instructed to consume the same meals the day before each trial and to have a pre-competition meal 3-4 h before the onset of the experiment. Fluid and diet guidelines were provided to increase the likelihood of carbohydrate availability and euhydration for the experimental trials. To produce a within-subject standardisation of diet, participants completed a 24-h dietary record before the first trial, and they replicated the same dietary pattern before the second trial. On the experimental days, participants arrived at their habitual training facility indoor court at 17:00 hours. After this, the assigned experimental capsule was ingested, and ingestion was verified by an experimenter. Prior to each evaluation session, the participants performed a standardised warm-up consisting of continuous running for $3 \mathrm{~min}$, dynamic joint mobility for $5 \mathrm{~min}$, and three progressive accelerations of less than $30 \mathrm{~m}$ [22]. Afterwards, participants underwent the battery of tests consisting of a countermovement jump (CMJ), 20-m sprint test and a specific futsal kicking test (Massey Futsal Shooting Test). The recovery between tests was of $5 \mathrm{~min}$. Ten minutes after the end of this futsalspecific testing, participants played a $2 \times 7.5$-minute simulated futsal match. Just after 
the completion of the match, participants completed a questionnaire about their sensations of power, endurance and perceived exertion during the whole experimental trial, using a 1-to-10- point scale [23]. Additionally, participants were provided with a survey to be filled out the following morning about sleep quality, activeness, gastrointestinal problems and other discomforts. This survey included several typical side-effects associated with caffeine on a yes/no scale, that has been used previously to assess the side effects derived from energy drink ingestion [24]. This survey also included specific questions to evaluate the success of the participant's blinding procedure.

\section{CMJ}

The CMJ test started with participants standing in the anatomical position but with hands on the hips. On command, participants flexed their knees to $90^{\circ}$ and jumped as high as possible while maintaining their hands on their hips. Jump height was measured with an infrared beam jump system (Optojump Next, Microgate, Bolzano, Italy) using the flight time. Two CMJ attempts were performed interspersed with 45 seconds of passive recovery as previously described [25]. The highest attempt was used for subsequent statistical analysis.

\section{0-metre sprint}

In the 20-m sprint test, the futsal players ran at maximal speed for 20-metres in a straight line, and the time needed to cover the distance was measured using two photocell gates placed $1 \mathrm{~m}$ above the ground (Polifemo Radio Light, Microgate, Bolzano, Italy). This test was selected based on a previous investigation with professional Brazilian futsal players [26]. Two attempts were performed interspersed with 5 minutes of passive recovery between repetitions. The faster attempt was used for subsequent statistical analysis. 


\section{Massey Futsal Shooting Test}

The Massey Futsal Shooting test started with the ball (FLL555-W-WOR FIFA PRO T4, Mikasa, Tokyo, Japan) placed on a marked circle located in the centre of the shooting zone (Figure 1). The player's position was to stand facing away from the goal, and at 11 $\mathrm{m}$ from the ball, in one of the corners of the shooting zone (A). On command, the futsal player sprinted to the ball (B), played a rebound pass off a bench (C), controlled the ball if necessary, turned and shot at the goal within the shooting zone (Figure 1) such as has been described previously [27]. Each player performed the test five times and ball velocity during each shot was measured with a radar gun (Stalker Radar Pro II, Applied Concepts, Texas, USA). Shooting accuracy was measured using a previously established score scale (from 1 to 5 points) depending on the zone where the goal was obtained (Figure 1). If the shot was not on goal, the score for that attempt was equal to zero. Participants had been informed about the scores of each zone. Shots were disregarded if the shot sequence (from initial movement to completion of the shot) took longer than $6 \mathrm{~s}$, the ball speed was $<60 \mathrm{~km} \mathrm{~h}^{-1}$, and/or the shot was attempted from outside of the shooting zone. An average of the five attempts (for both velocity and scores) was used for statistical analysis. Players were not informed of their shooting speed to avoid bias between measurements.

\section{$* * *$ Figure 1 about here ${ }^{* * *}$}

\section{Simulated futsal match}

Players participated in a simulated match played on an official futsal court and following the rules of the World Futsal Federation (except for the game duration). To allow the participation of all players according to the official rules of futsal (4 field players and one goalkeeper), two different futsal matches were played in each experimental trial. Each 
futsal game consisted of 2 halves of 7.5 minutes with a break of 2 minutes between halves. To avoid the effects of the rival level on the results of this study, the two teams competing were composed of the same ten players and they played in their specific positions. To avoid the effect of the substitutions on the results of the investigation, substitutions were not allowed, and all players completed the 2 halves of 7.5 minutes. A professional referee made decisions on play disputes. Before the onset of the match, all players were equipped with an inertial measurement unit based on ultra-wideband local position tracking system technology (100 Hz; WIMUPROTM; RealTrack Systems, Almería, Spain) which was placed in a Lycra vest (Wimu, Almería, Spain) to locate the inertial measurement unit between the shoulders [28]. The inertial measurement unit devices were calibrated and installed around the court as previously described [29]. The players wore the same inertial unit for both experimental trials to reduce measurement error. Total running distance covered during the match, high-speed running $\left(>14.4 \mathrm{~km} / \mathrm{h}^{-1}\right)$, maximal speed, number of sprints $\left(>19.8 \mathrm{~km} / \mathrm{h}^{-1}\right)$ number of high intensity accelerations (i.e., $>2 \mathrm{~m} / \mathrm{s}^{-2}$ ), decelerations (i.e., $<-2 \mathrm{~m} / \mathrm{s}^{-2}$ ), player load, metabolic power and high metabolic load distance were measured [30].

\section{Statistical analysis}

Data are presented as mean $\pm \mathrm{SD}$. Normality of each variable was tested using the Shapiro-Wilk test. Differences between experimental conditions (caffeine vs. placebo) were determined using paired t tests, and differences were considered as statistically relevant at $p<0.05$. Effect size were also calculated in all pairwise comparisons, using Cohen's $d$ and the effect size was interpreted using Cohen's categorisation. Differences between experimental conditions in the 1- to 10-point scale used for the self-reported feelings of muscle power, endurance, and overall perceived exertion during the game were identified using the Wilcoxon signed-rank test. McNemar's test was also used to 
detect differences in the prevalence of side effects. Data analysis was performed using SPSS (version 22.0; SPSS Inc, Chicago, IL, USA).

\section{RESULTS}

\section{CMJ and 20-m sprint}

In comparison to the placebo, $\mathrm{CMJ}$ height was greater by $2.8 \pm 5.2 \%$ with caffeine ingestion ( $p=0.048 ; \mathrm{ES}=0.29$, Figure 2A). In addition, 20 -m sprint time was reduced by $-2.2 \pm 4.2 \%(p=0.044 ; \mathrm{ES}=-0.54$, Figure $2 \mathrm{~B})$ with the ingestion of caffeine over the placebo.

\section{Massey Futsal Shooting Test}

In comparison to the placebo, the acute intake of caffeine did not modify ball velocity $(p=0.259 ; \mathrm{ES}=0.19$, Figure $2 \mathrm{C})$ or shooting accuracy $(p=0.848 ; \mathrm{ES}=0.07$, Figure 2D) during the Massey futsal shooting test.

\section{$* * *$ Figure 2 about here $* * *$}

\section{Simulated futsal match demands}

Futsal match-play running performance is presented in Table 1. In comparison to the placebo trial, the intake of caffeine increased the distance covered at $>14.4 \mathrm{~km} / \mathrm{h}$ (i.e., high-speed running distance), and the number of body impacts, the number of accelerations and the number of decelerations (all $p<0.050$; ES $>0.27$ ). However, there were no between-trial differences in peak running velocity, number of sprints, total running distance, or in the variables associated with player's load and power.

\section{$* * *$ Table 1 about here $* * *$}

\section{Side-effect questionnaire}


During the study, the futsal players reported similar self-perceived endurance (placebo $5.75 \pm 1.00$ vs. caffeine $6.13 \pm 0.96$ points; $p=0.319, \mathrm{ES}=0.38)$, power $(6.19 \pm$ 0.98 vs. $6.63 \pm 1.15$ points; $p=0.203, \mathrm{ES}=0.41)$, and fatigue $(5.50 \pm 1.03$ vs. $5.38 \pm 0.81$ points; $p=0.652, \mathrm{ES}=0.12$ ). During the hours after the testing, the futsal players showed a similar prevalence of side effects in the two experimental protocols (Table 2). Only $43.75 \%$ (7 out of 16) participants correctly guessed the order of the trials, indicating successful blinding of the participants to the interventions.

\section{$* * *$ Table 2 about here $* * *$}

\section{DISCUSSION}

Caffeine is recognised as a useful ergogenic aid for improving neuromuscular performance $[12,31]$ or match-play demands in team sports disciplines $[10,11,15]$. However, the evidence of benefits derived from acute caffeine ingestion is scarce in futsal $[17,18]$ and to our knowledge, no previous studies have analysed the effects of caffeine ingestion on real or simulated match-play in futsal. Thus, the aim of this study was to determine the effect of caffeine ingestion on futsal-specific testing and on match-play running performance during a simulated game. According to our data, in comparison to the administration of a placebo, the acute intake of $3 \mathrm{mg} / \mathrm{kg}$ of caffeine showed an improvement in players' jump height (2.8\%) a reduction of 20 -m sprint time $(-2.2 \%)$ and greater high-speed running distance (19.6\%), accelerations $(4.2 \%)$, decelerations $(4.3 \%)$ and body impacts $(8.1 \%)$ during a simulated match. Collectively, these outcomes suggest that caffeine supplementation with a moderate dose can be considered as an effective ergogenic protocol to obtain meaningful improvements in several aspects of futsal performance. 
In futsal, ball kicking velocity is one of the performance variables more closely related to futsal-specific performance $[4,32]$ and a common and determinant attacking skill which allows players to score. In the current investigation, the effects of caffeine on kicking ball velocity were measured with a complex futsal specific test that included a sprint, a pass, and a powerful shot at the goal. When compared to the placebo trial, caffeine did not induce any statistical difference in this test, or in ball velocity or accuracy. Although no previous studies have analysed the effect of $3 \mathrm{mg} / \mathrm{kg}$ of caffeine in futsal players, the effectiveness of this ergogenic aid has been shown in other similar sportsspecific situations such as in volleyball spiking [13,14] and handball shooting [12]. However, the lack of effectiveness of caffeine to enhance this type of near-to-maximal intensity action has been found for the tennis serve [33]. The reasons explaining the different outcomes of these investigations are not evident as in all situations the dose of caffeine was the same (i.e., $3 \mathrm{mg} / \mathrm{kg}$ ), and the study sample was composed of trained individuals with long experience in the action under investigation. On the other hand, the evidence is clearer to depict that caffeine has little or no effect on sports-specific accuracy such as in basketball free throws [34] or 2-point/3-point field goals [11] or in other ball games [35]. In any case, in the light of the current results, it seems adequate to suggest that the ingestion of caffeine before training /matches will not have any measurable effect to increase shooting ball velocity or accuracy in elite futsal players.

In futsal, possessing excellent muscle power, velocity and agility are key for performance as the characteristics of the game, including the number of players, the pitch dimensions and the unlimited number of substitutions, make futsal an intense team sport [36]. In this regard, the number of sprints and the distance covered at high intensity are decisive for the final match outcome, as some of the crucial match actions are often preceded by a previous sprint [37]. Previous studies have reported that the distance 
covered at sprinting speed is between $5 \%$ to $9 \%$ of the total distance covered during a futsal match $[8,38]$ and makes it possible to discriminate between elite players and subelite players [39]. In the current study, futsal-specific testing and the simulated match showed valuable benefits of caffeine in terms of muscle power, velocity, and highintensity running distance during match play. First, caffeine improved CMJ height which is a recurrent finding in the literature with similar improvements in volleyball players [13], football players [10], basketball players [11] and in other individual sports such as badminton [40], and swimmers [9]. Additionally, caffeine reduced sprint time, a finding also present in other team sports such as basketball [31] and handball [12]. Lastly, caffeine increased the running distance covered at above $14.4 \mathrm{~km} / \mathrm{h}$ without affecting total running distance; specifically, the running distance changed from $9.65 \%$ of the total distance during the match with the placebo to $11.8 \%$ of the match with caffeine. Again, enhanced high-intensity running during simulated or real matches has also been found in football [10], different rugby modalities [41,42] hockey [15] and among other team-sport disciplines [16]. Collectively, this information establishes that caffeine is an effective ergogenic aid to enhance jump height, sprint velocity and high-intensity running distance in team-sport players.

An interesting finding of this investigation is the effect of caffeine on the number of accelerations/decelerations and on the number of body impacts. The number of accelerations/decelerations was measured by changes in the position of the players on the court with the local positioning system. The number of impacts was measured by the built-in accelerometer in the inertial measurement unit. Irrespective of the technology used, the enhancement of the number of accelerations/decelerations and number of impacts indicates that the player had a more active role during the simulated match. These technologies do not allow definition of what actions the players were involved in, but it 
is probable that caffeine improved the number of changes of directions, the quantity of tackles (produced or received), and the player's overall involvement during match play. This outcome, found in other team $[11,12,14,42,43]$ and individual sports $[33,40]$ is an indirect but meaningful marker to indicate that acute caffeine intake causes athletes to be more involved in the game during match play. Further investigations with videotechnology are needed to determine the particular effect of caffeine in futsal-specific actions during match play.

Finally, the results of the post-match surveys about self-reported feelings of performance did not indicate any difference between caffeine or placebo ingestion. Interestingly, futsal players did not report greater feelings of fatigue with caffeine despite having a more active role in match play with a greater high-intensity running distance. This means that caffeine enables higher futsal performance without affecting exertion. Additionally, there was no difference in the prevalence of side effects reported in the hours after the ingestion of the treatment. Previous studies indicate that team-sport players habitually feel more nervousness, and insomnia and are more active after the ingestion of caffeine [24]. The explanation of the difference between the results of this investigation and previous literature is not evident as the dose of caffeine, level of athletes or survey used were the same. It is probable that the sample size of the current investigation limited the obtention of differences for the prevalence of side effects as we employed a yes/no questionnaire.

\section{LIMITATIONS}

The current investigation has several limitations. First, the simulated match was shorter in duration that an official futsal match. Therefore, it is probable that the fatigue that this simulated match induced was lower compared to an official futsal match, 
potentially reducing the benefits of caffeine. Future investigations should be conducted to determine the effect of caffeine in a real competitive futsal context. Second, we only studied the effect of a small dose of caffeine (i.e., $3 \mathrm{mg} / \mathrm{kg}$ ) and it is unknown if a higher dose could produce greater benefits in both futsal-specific testing and match play. Additionally, we selected a sample of low caffeine consumers and it is probable that the effect of caffeine supplementation is of lower magnitude in habitual caffeine consumers, as tolerance to the ergogenic effect of caffeine has been recently reported [44]. Third, the findings of this study should only be translated to well-trained men futsal players and future studies should determine if the effects associated with caffeine ingestion are similar in women futsal players or futsal players with a lower training background.

\section{CONCLUSIONS}

Acute caffeine supplementation, in a dose of $3 \mathrm{mg} / \mathrm{kg}$ of body mass, enhanced several physical variables associated with futsal performance such as jumping height, and sprint speed and it improved high speed running, accelerations/decelerations and body impacts during a simulated futsal match. Additionally, this dose of caffeine produced a low prevalence of side effects which were comparable to the ones produced after the ingestion of a placebo. Therefore, caffeine can be considered as an effective supplementation substance for men futsal players. From a practical viewpoint, caffeine dosage should be on an individual basis as the ergogenic response to caffeine presents certain interindividual variability [45]. Testing caffeine before use in competition is highly recommended, while the avoidance of habitual caffeine intake may be positive to augment the effect of caffeine intake [44] and reduce side effects [46]. 
Acknowledgements: The authors wish to thank the subjects for thei invaluable contribution to the study.

Funding: This investigation did not receive any funding 


\section{REFERENCES}

1. Beato M, Coratella G, Schena F (2016) Brief review of the state of art in futsal. J Sports Med Phys Fitness 56 (4):428-432

2. Lopez-Segovia M, Vivo Fernandez I, Herrero Carrasco R, Pareja Blanco F (2019) Preseason Injury Characteristics in Spanish Professional Futsal Players: The LNFS Project. J Strength Cond Res. doi:10.1519/JSC.0000000000003419

3. Ramos-Campo DJ, Rubio-Arias JA, Carrasco-Poyatos M, Alcaraz PE (2016) Physical performance of elite and subelite Spanish female futsal players. Biol Sport 33 (3):297-304. doi:10.5604/20831862.1212633

4. Vieira LH, de Souza Serenza F, de Andrade VL, de Paula Oliveira L, Mariano FP, Santana JE, Santiago PR (2016) Kicking Performance and Muscular Strength Parameters with Dominant and Nondominant Lower Limbs in Brazilian Elite Professional Futsal Players. J Appl Biomech 32 (6):578-585. doi:10.1123/jab.2016-0125

5. Ribeiro JN, Goncalves B, Coutinho D, Brito J, Sampaio J, Travassos B (2020) Activity Profile and Physical Performance of Match Play in Elite Futsal Players. Front Psychol 11:1709. doi:10.3389/fpsyg.2020.01709

6. Naser N, Ali A, Macadam P (2017) Physical and physiological demands of futsal. J Exer Sci Fit 15 (2):76-80. doi:10.1016/j.jesf.2017.09.001

7. Illa J, Fernandez D, Reche X, Serpiello F (2021) Positional Differences in the Most Demanding Scenarios of External Load Variables in Elite Futsal Matches. Front Psychol 12:625126

8. Alvarez JC, D'Ottavio S, Vera JG, Castagna C (2009) Aerobic fitness in futsal players of different competitive level. J Strength Cond Res 23 (7):2163-2166. doi:10.1519/JSC.0b013e3181b7f8ad

9. Lara B, Gonzalez-Millan C, Salinero JJ, Abian-Vicen J, Areces F, BarberoAlvarez JC, Munoz V, Portillo LJ, Gonzalez-Rave JM, Del Coso J (2014) Caffeinecontaining energy drink improves physical performance in female soccer players. Amino Acids 46 (5):1385-1392. doi:10.1007/s00726-014-1709-z

10. Del Coso J, Munoz-Fernandez VE, Munoz G, Fernandez-Elias VE, Ortega JF, Hamouti N, Barbero JC, Munoz-Guerra J (2012) Effects of a caffeine-containing energy drink on simulated soccer performance. PLoS ONE 7 (2):e31380. doi:10.1371/journal.pone.0031380

11. Puente C, Abian-Vicen J, Salinero JJ, Lara B, Areces F, Del Coso J (2017) Caffeine Improves Basketball Performance in Experienced Basketball Players. Nutrients 9 (9). doi:10.3390/nu9091033

12. Munoz A, Lopez-Samanes A, Perez-Lopez A, Aguilar-Navarro M, MorenoHeredero B, Rivilla-Garcia J, Gonzalez-Frutos P, Pino-Ortega J, Morencos E, Del Coso $\mathrm{J}$ (2020) Effects of Caffeine Ingestion on Physical Performance in Elite Women Handball Players: A Randomized, Controlled Study. Int J Sports Physiol Perform 1-8. doi:10.1123/ijspp.2019-0847

13. Del Coso J, Perez-Lopez A, Abian-Vicen J, Salinero JJ, Lara B, Valades D (2014) Enhancing physical performance in male volleyball players with a caffeine-containing energy drink. Int J Sports Physiol Perform 9 (6):1013-1018. doi:10.1123/ijspp.2013-0448 14. Perez-Lopez A, Salinero JJ, Abian-Vicen J, Valades D, Lara B, Hernandez C, Areces F, Gonzalez C, Del Coso J (2015) Caffeinated energy drinks improve volleyball performance in elite female players. Med Sci Sports Exerc 47 (4):850-856. doi:10.1249/MSS.0000000000000455 
15. Del Coso J, Portillo J, Salinero JJ, Lara B, Abian-Vicen J, Areces F (2016) Caffeinated Energy Drinks Improve High-Speed Running in Elite Field Hockey Players. Int J Sport Nutr Exerc Metab. 26 (1):26-32. doi:10.1123/ijsnem.2015-0128

16. Salinero JJ, Lara B, Del Coso J (2019) Effects of acute ingestion of caffeine on team sports performance: a systematic review and meta-analysis. Res Sport Med 27 (2):238-256. doi:10.1080/15438627.2018.1552146

17. Wassmansdorf R, Dalapícola Alves I, Schreiber M, de Mello R, Szuck P, Ribas M, Sato-Urbinati K, Bassan J (2012) Efeito da ingestao de cafeína em atletas de futsal. Rev Bras Futs Fut 4 (13):223-228

18. Bezerra G, Gomes EDS, Correia-Oliveira CR (2021) Caffeine Ingestion Affects Performance in Different Parts of a Novel Multidirectional High-Intensity Intermittent Exercise in Futsal Athletes. J Am Coll Nutr:1-8. doi:10.1080/07315724.2020.1852450

19. Filip A, Wilk M, Krzysztofik M, Del Coso J (2020) Inconsistency in the Ergogenic Effect of Caffeine in Athletes Who Regularly Consume Caffeine: Is It Due to the Disparity in the Criteria That Defines Habitual Caffeine Intake? Nutrients 12 (4). doi:10.3390/nu12041087

20. Faul F, Erdfelder E, Lang AG, Buchner A (2007) G*Power 3: a flexible statistical power analysis program for the social, behavioral, and biomedical sciences. Behav Res Method 39 (2):175-191. doi:10.3758/bf03193146

21. Mora-Rodriguez R, Pallares JG, Lopez-Gullon JM, Lopez-Samanes A, Fernandez-Elias VE, Ortega JF (2015) Improvements on neuromuscular performance with caffeine ingestion depend on the time-of-day. J Sci Med Sport 18 (3):338-342. doi:10.1016/j.jsams.2014.04.010

22. Ayarra R, Nakamura FY, Iturricastillo A, Castillo D, Yanci J (2018) Differences in Physical Performance According to the Competitive Level in Futsal Players. J Hum Kinet 64:275-285. doi:10.1515/hukin-2017-0201

23. Lara B, Ruiz-Vicente D, Areces F, Abian-Vicen J, Salinero JJ, Gonzalez-Millan C, Gallo-Salazar C, Del Coso J (2015) Acute consumption of a caffeinated energy drink enhances aspects of performance in sprint swimmers. Br J Nut 114 (6):908-914. doi:10.1017/S0007114515002573

24. Salinero JJ, Lara B, Abian-Vicen J, Gonzalez-Millan C, Areces F, Gallo-Salazar C, Ruiz-Vicente D, Del Coso J (2014) The use of energy drinks in sport: perceived ergogenicity and side effects in male and female athletes. Br J Nut 112 (9):1494-1502. doi:10.1017/S0007114514002189

25. Bosco C, Luhtanen P, Komi PV (1983) A simple method for measurement of mechanical power in jumping. Eur J Appl Physiol. 50 (2):273-282. doi:10.1007/BF00422166

26. Nakamura FY, Pereira LA, Rabelo FN, Ramirez-Campillo R, Loturco I (2016) Faster Futsal Players Perceive Higher Training Loads and Present Greater Decreases in Sprinting Speed During the Preseason. J Strength Cond Res 30 (6):1553-1562. doi:10.1519/JSC.0000000000001257

27. Naser N, Ali A (2016) A descriptive-comparative study of performance characteristics in futsal players of different levels. J Sports Sci 34 (18):1707-1715. doi:10.1080/02640414.2015.1134806

28. Bastida-Castillo A, Gomez-Carmona CD, De La Cruz Sanchez E, Pino-Ortega J (2019) Comparing accuracy between global positioning systems and ultra-widebandbased position tracking systems used for tactical analyses in soccer. Eur J Sport Sci 19 (9):1157-1165. doi:10.1080/17461391.2019.1584248

29. Bastida Castillo A, Gomez Carmona CD, De la Cruz Sanchez E, Pino Ortega J (2018) Accuracy, intra- and inter-unit reliability, and comparison between GPS and 
UWB-based position-tracking systems used for time-motion analyses in soccer. Eur J Sport Sci 18 (4):450-457. doi:10.1080/17461391.2018.1427796

30. Folgado H, Duarte R, Marques P, Sampaio J (2015) The effects of congested fixtures period on tactical and physical performance in elite football. J Sports Sci 33 (12):1238-1247. doi:10.1080/02640414.2015.1022576

31. Raya-Gonzalez J, Scanlan AT, Soto-Celix M, Rodriguez-Fernandez A, Castillo D (2021) Caffeine Ingestion Improves Performance During Fitness Tests but Does Not Alter Activity During Simulated Games in Professional Basketball Players. Int J Sports Physiol Perform:1-8. doi:10.1123/ijspp.2020-0144

32. Sekulic D, Pojskic H, Zeljko I, Pehar M, Modric T, Versic S, Novak D (2020) Physiological and Anthropometric Determinants of Performance Levels in Professional Futsal. Front Psychol 11:621763. doi:10.3389/fpsyg.2020.621763

33. Gallo-Salazar C, Areces F, Abian-Vicen J, Lara B, Salinero JJ, Gonzalez-Millan C, Portillo J, Munoz V, Juarez D, Del Coso J (2015) Enhancing physical performance in elite junior tennis players with a caffeinated energy drink. Int J Sports Physiol Perform 10 (3):305-310. doi:10.1123/ijspp.2014-0103

34. Tan ZS, Burns SF, Pan JW, Kong PW (2020) Effect of caffeine ingestion on freethrow performance in college basketball players. J Exer Sci Fitness 18 (2):62-67. doi:10.1016/j.jesf.2019.12.002

35. Chia JS, Barrett LA, Chow JY, Burns SF (2017) Effects of Caffeine Supplementation on Performance in Ball Games. Sport Med 47 (12):2453-2471. doi:10.1007/s40279-017-0763-6

36. Dos-Santos JW, da Silva HS, da Silva Junior OT, Barbieri RA, Penafiel ML, da Silva RNB, Milioni F, Vieira LHP, Coledam DHC, Santiago PRP, Papoti M (2020) Physiology Responses and Players' Stay on the Court During a Futsal Match: A Case Study With Professional Players. Front Psychol 11:620108. doi:10.3389/fpsyg.2020.620108

37. Faude O, Koch T, Meyer T (2012) Straight sprinting is the most frequent action in goal situations in professional football. J Sports Sci 30 (7):625-631. doi:10.1080/02640414.2012.665940

38. De Oliveira Bueno MJ, Caetano FG, Pereira TJ, De Souza NM, Moreira GD, Nakamura FY, Cunha SA, Moura FA (2014) Analysis of the distance covered by Brazilian professional futsal players during official matches. Sport Biomech 13 (3):230240. doi:10.1080/14763141.2014.958872

39. Spyrou K, Freitas TT, Marin-Cascales E, Alcaraz PE (2020) Physical and Physiological Match-Play Demands and Player Characteristics in Futsal: A Systematic Review. Front Psychol 11:569897. doi:10.3389/fpsyg.2020.569897

40. Abian P, Del Coso J, Salinero JJ, Gallo-Salazar C, Areces F, Ruiz-Vicente D, Lara B, Soriano L, Munoz V, Abian-Vicen J (2015) The ingestion of a caffeinated energy drink improves jump performance and activity patterns in elite badminton players. J Sports Sci 33 (10):1042-1050. doi:10.1080/02640414.2014.981849

41. Del Coso J, Ramirez JA, Munoz G, Portillo J, Gonzalez-Millan C, Munoz V, Barbero-Alvarez JC, Munoz-Guerra J (2013) Caffeine-containing energy drink improves physical performance of elite rugby players during a simulated match. Appl Physiol Nutr Metab 38 (4):368-374. doi:10.1139/apnm-2012-0339

42. Del Coso J, Portillo J, Munoz G, Abian-Vicen J, Gonzalez-Millan C, MunozGuerra J (2013) Caffeine-containing energy drink improves sprint performance during an international rugby sevens competition. Amino Acids 44 (6):1511-1519. doi:10.1007/s00726-013-1473-5 
43. Portillo J, Del Coso J, Abian-Vicen J (2017) Effects of Caffeine Ingestion on Skill Performance During an International Female Rugby Sevens Competition. J Strength Cond Res 31 (12):3351-3357. doi:10.1519/JSC.0000000000001763

44. Lara B, Ruiz-Moreno C, Salinero JJ, Del Coso J (2019) Time course of tolerance to the performance benefits of caffeine. PLoS ONE 114 (1):e0210275. doi:10.1371/journal.pone.0210275

45. Del Coso J, Lara B, Ruiz-Moreno C, Salinero JJ (2019) Challenging the Myth of Non-Response to the Ergogenic Effects of Caffeine Ingestion on Exercise Performance. Nutrients 11 (4). doi:10.3390/nu11040732

46. Ruiz-Moreno C, Lara B, Salinero JJ, Brito de Souza D, Ordovas JM, Del Coso J (2020) Time course of tolerance to adverse effects associated with the ingestion of a moderate dose of caffeine. Eur J Nutr 59 (7):3293-3302. doi:10.1007/s00394-019-021672 


\section{TABLES AND FIGURES}

Table 1. Running performance during a simulated futsal match (2 halves of $7.5 \mathrm{~min}$ ) after the ingestion of $3 \mathrm{mg} / \mathrm{kg}$ of caffeine or a placebo in futsal players.

Table 2. Prevalence of side effects in the hours following the ingestion of $3 \mathrm{mg} / \mathrm{kg}$ of caffeine or a placebo in futsal players.

Figure 1. Graphical description of the Massey Futsal Shooting Test

Figure 2. Height during a countermovement jump (A), time during a 20-m sprint test (B), ball velocity (C) and shooting accuracy during the Massey Futsal Shooting Test after the ingestion of $3 \mathrm{mg} / \mathrm{kg}$ of caffeine or the placebo in futsal players. Data are mean $\pm \mathrm{SD}$ for 16 high-performance futsal players. (*) Caffeine different from placebo at $p<0.050$. 
B)
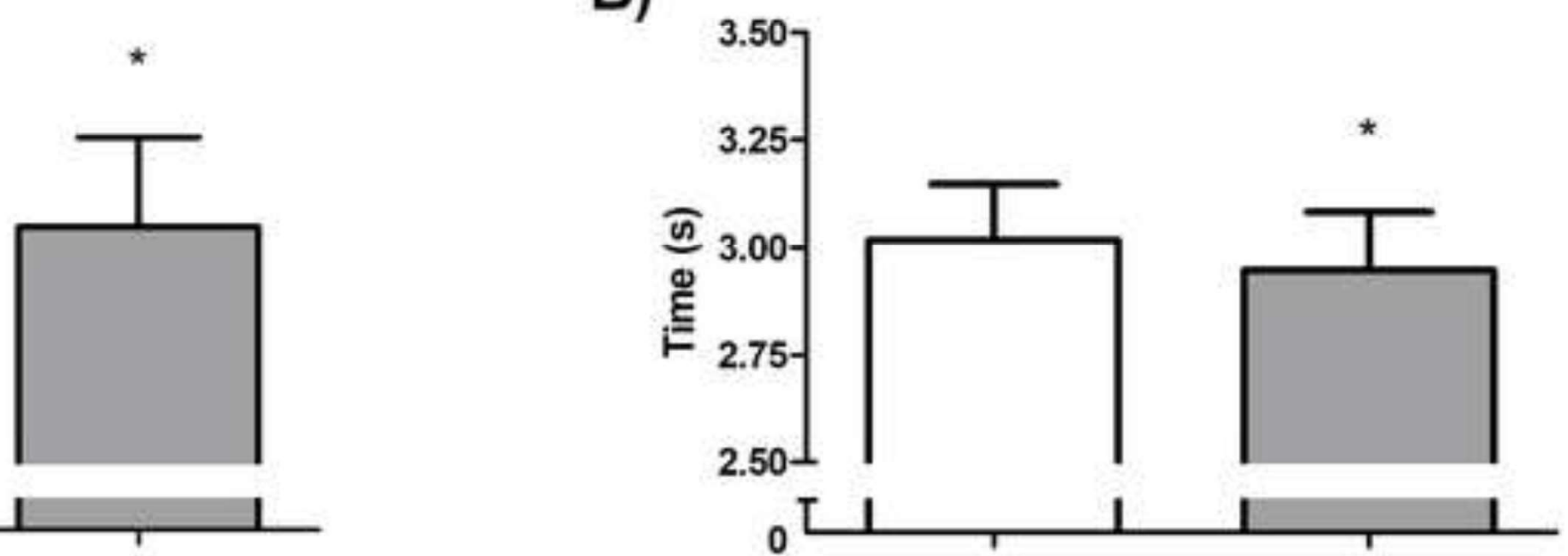

D)

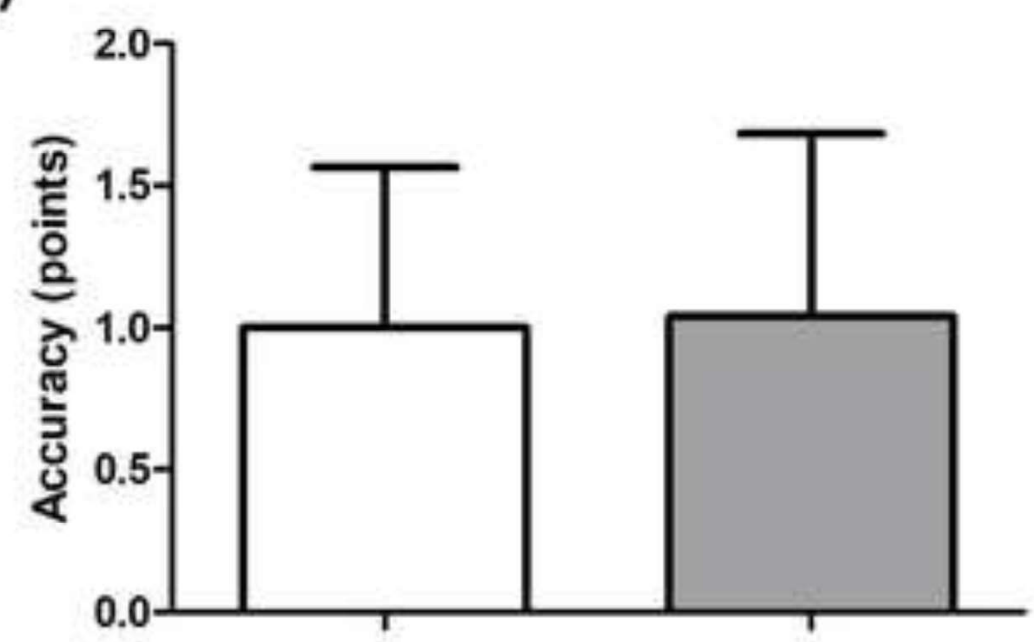

Placebo

Caffeine 
Table 1. Running performance during a simulated futsal match ( 2 halves of $7.5 \mathrm{~min}$ ) after the ingestion of 3 futsal players.

\section{Variable (units)}

Peak running velocity $\left(\mathrm{km} \cdot \mathrm{h}^{-1}\right)$

Running distance $\left(\mathrm{m} \mathrm{min}^{-1}\right)$

High speed running $\left(\mathrm{m} \mathrm{min}^{-1}\right)$

Sprints (number $\min ^{-1}$ )

Accelerations (number $\mathrm{min}^{-1}$ )

Decelerations (number $\mathrm{min}^{-1}$ )

Body impacts (number $\min ^{-1}$ )

Player load (arbitrary units)

Metabolic power $\left(\mathrm{W} \cdot \mathrm{kg}^{-1} \mathrm{~min}^{-1}\right)$

High metabolic load distance $\left(\mathrm{W} \cdot \mathrm{kg}^{-1} \mathrm{~min}^{-1}\right)$

\section{Placebo}

$19.72 \pm 0.69$

$19.72 \pm 0.51$

$40.82 \pm 2.48$

$40.11 \pm 2.12$

$3.94 \pm 1.23$

$4.75 \pm 1.21$

$0.25 \pm 0.15$

$0.31 \pm 0.13$

$18.12 \pm 1.23$

$18.82 \pm 0.98$

$18.01 \pm 1.23$

$18.74 \pm 0.99$

$8.17 \pm 2.66$

$8.89 \pm 3.16$

$0.74 \pm 0.34$

$0.76 \pm 0.31$

$280.20 \pm 31.36$

$286.19 \pm 16.85$

$10.13 \pm 2.18$

$10.19 \pm 1.75$

Data are mean \pm SD for 16 high-performance futsal players. All variables are normalized by the time play Caffeine different from placebo at $p<0.050$. 
Table 2. Prevalence of side effects after the ingestion of $3 \mathrm{mg} / \mathrm{kg}$ of caffeine or the placebo in futsal players.

Items

Placebo Caffeine $p$

\begin{tabular}{lccc}
\hline Insomnia (\%) & 12.5 & 31.25 & 0.200 \\
\hline Gastrointestinal problems (\%) & 6.25 & 18.75 & 0.285 \\
\hline Increased activeness (\%) & 18.75 & 18.75 & 1.000 \\
\hline Irritability (\%) & 12.50 & 12.50 & 1.000 \\
\hline Muscle pain (\%) & 12.50 & 18.75 & 0.626 \\
\hline Tachycardia and heart palpitations (\%) & 6.25 & 18.75 & 0.285 \\
\hline Headache (\%) & 6.25 & 6.25 & 1.000 \\
\hline Increased excretion of urine (\%) & 12.50 & 25.0 & 0.365 \\
\hline Increased fatigue (\%) & 6.25 & 6.25 & 1.000 \\
\hline Nervousness (\%) & 0.00 & 6.25 & 0.310 \\
\hline
\end{tabular}

Data are percentage of affirmative responses to each of the side-effect for 16 high-performance futsal players 